to scientific communications presenting new points of view, and the afternoons to administrative details. This arrangement was disturbed in the course of the week in order to provide more time for administrative questions.

The sessions for scientific discussions were opened by a paper by Prof. V. Bjerknes giving theoretical explanations, on the basis of wave motion at the mutual boundary of two discontinuous media, of the series of phenomena which had been set out by his son, representing the result of observations upon the Polar front in cyclones. This was followed by a paper by Sir Napier Shaw on the structure of the atmosphere and its thermodynamics, to suggest a thermodynamic basis for the study of convection in the atmosphere, and the transformations of energy associated therewith. A paper by L. F. Richardson directed attention to the necessity for studying pilotballoon observations in relation to the continuity of mass, a subject which in spite of its importance has hitherto not received adequate treatment. Prof. van Everdingen gave an account of a method of obtaining regular observations of pressure, temperature, and humidity in the upper air by means of aeroplanes, using a balloon meteorograph with the usual clockwork drum; such observations had been carried out on upwards of 340 occasions in the past year at Soesterberg and other stations in Holland. S. Fujiwhara, of Tokyo, discussed turbulent movements which are to be observed in clouds, and their relation to eddies in water. Dr. W. van Bemmelen, of Java, gave an account of comprehensive results of great importance of observations of wind in the upper atmosphere up to 30 kilometres, obtained at the observatory at Batavia. H. Köhler, of Holdda, discussed the study of the condensation of water vapour in a cold atmosphere into ice crystals and supercooled water drops, and the effects which may be attributed to very small quantities of chlorides.

L. F. Richardson discussed the application of the geostropic principle to winds in the stratosphere. Dr. A. de Quervain, of Zurich, brought up proposals for the establishment of a geophysical observatory at the terminus of the Jungfrau railway, at a height of 3600 metres, which received the cordial commendation of the meeting. P. Schereschewskv, of the Corps of Mines, Paris, explained the method of determining the winds in the upper air by means of sound-ranging applied to detonators carried by pilot balloons, a method which is applicable alike in clear and cloudy weather. R. Sekiguti, of the Observatory of Kobe, explained the application in forecasting of isobaric charts for the level of three kilometres. Col. L. Matteuzzi, director of the Meteorological Service of Italy, presented an atlas of the principal cloud forms, and explained a method of applying the periodicity of barometric oscillations to the anticipation of barometric distribution in the future. O. Devik, of Tromsø, described a new method of observing balloons and its application in forecasting. G. I. Taylor gave an account of the result of his investigation of turbulence in the atmosphere and its symmetric propagation in the three dimensions. M. Dongier discusser the observations of temperature and wind at the Eiffel
Tower and the discontinuities which they disclose. J. Bjerknes directed attention to the unique accumulation of observations of the upper air during the war which had been communicated to the president by the countries on both sides, and gave illustrations of the observations on selected occasions in the study of the method of the Polar front. P. Schereschewsky gave an account of some new methods of forecasting, and the proceedings of the meetings for scientific discussion were concluded with a paper by L. F. Richardson on ideal arrangements of stations on the map for the purpose of numerical computations for forecasting.

The business meetings were devoted largely to the development of a scheme for the collection, compilation, and publication of observations in the upper air on an international basis, in continuation, with such modifications as experience has suggested, of the international scheme which was agreed upon at Petrograd in 1904 and supported by subventions from Government organisations of nineteen countries. The outline of a proposal was agreed upon, and the president was requested to report it to the meeting of the International Meteorological Committee to be held in London in September. The commission adopted resolutions in favour of a geophysical observatory on the Jungfrau, and also appointed a subcommittee to deal with the question of the anomalies in the audibility of the sound of explosions, which was also the subject of a communication by Dr. de Quervain.

It was noticeable that the commission devoted the greater part of its attention to the mode of dealing with the observations of the upper air based upon the supposition that there should be twenty-four days in the year on which balloons for sounding the highest layers of the meteorological atmosphere, including the stratosphere, should be sent up in a sufficient number of countries to secure a general representation of the whole. At present the number of observations is extremely limited, and the reorganisation of the observations would need the support of meteorologica! institutes in many parts of the world. Beyond pointing out the urgent necessity for such observations over the sea, the technique of which had already been worked out by Teisserenc de Bort and the German meteorologists, but which had not become international in any sense, the commission confined itself to a general invitation to the meteorological organisations of the globe for co-operation on the international days.

An account of the proceedings of the meetings would be incomplete without reference to the hospitality of the citizens of Bergen. It will be remembered that the greater part of the inner town was destroyed by a disastrous fire five years ago, and it has not yet been rebuilt; all the hotel accommodation was required for tourists, and the delegates to the meeting were all entertained with cordial hospitality by the foreign Consuls and the citizens of Bergen, and also honoured by an official dinner given by the municipality, at which the Chief Burgomaster presided. The municipality also placed its ancient and picturesque Council House at the disposal of the commission for the meetings.

\title{
A Small Brinell Hardness Testing Machine.
}

$\mathrm{H}$ ARDNESS, as recent correspondence in NATURE (vol. cvi., pp. 377, 440, 534, 599, 662, November, I920-January, I92 I) has shown, is a subject of interest to both the engineer and the physicist. Whatever may be the exact physical significance of the term, there can be no doubt that measurements of this property, or group of properties, are of increasing practical importance. In the Brinell method of measuring hardness, as commonly applied, a steel ball of diameter about $1 \mathrm{~cm}$. is applied to the surface of the test piece under a load of the order of $3000 \mathrm{~kg}$., and the size of the resulting impression is measured. In practice NO. 2702 , VOL. IO7] 
the use of a ball of this size is limited to specimens not much less than one-tenth of an inch in thickness and half an inch in width. In I9I3 the necessity arose for the accurate determination of the hardness of the walls of small-arm cartridge-cases at different positions along the length. The thickness of wall, diminishing in some cases to about one-hundredth of an inch near the shoulder, is quite insufficient for the application of the usual Brinell test. Accordingly, a machine was designed and constructed by Messrs. H. Moore and R. Mather for the Research Department, Woolwich, in which very small balls with correspondingly small loads could be employed. A description of this machine has been given by $\mathrm{Mr}$. Moore in

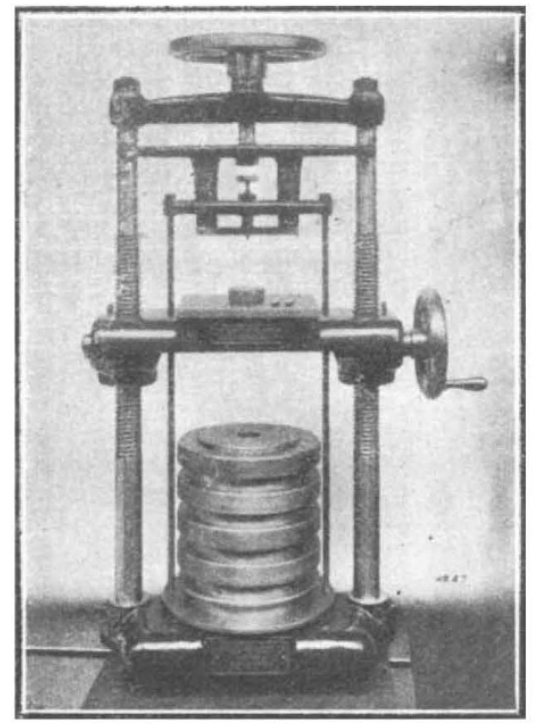

Frg. r.-A small Brinell hardness testing machine.

the Proceedings of the Institution of Mechanical Engineers of January, I92 I. It was designed to permit of great latitude in the dimensions of the test specimen, of the use of various sizes of ball from I $\mathrm{mm}$. diameter upwards, and of loads from 5 to roo kg. The first machine was in continuous use during the war, and was the subject of a secret patent (Craig, Moore, and Mather's patent), which, however, has now been published. The illustration (Fig. I) shows a simplified form of the machine constructed by Messrs. Alfred Herbert, Ltd., of Coventry.

The machine stands upon a base-plate furnished with levelling screws. This plate supports two vertical threaded columns which carry the table for the reception of the specimens to be tested. By turnings the hand-wheel at the side of the machine the table may be set at the required height. The load seen in the lower part of the photograph is composed of $a$ set of graduated cylindrical weights totalling $50 \mathrm{~kg}$. It is carried by the loading stirrup, to the upper portion of which is attached the ball-holder. The ball is fastened to the ball-holder by india-rubber solution so as to render the changing of balls an easy matter. The most important point in the design of the apparatus is the method by which the load is transferred from the cross - head of the machine to the specimen under test. By turning the hand-wheel at the top a non-rotating screw of fine pitch can be raised or lowered. The lower end of the screw carries a suspension stirrup, which is prevented from rotating by arms bearing against the columns, and from this suspension stirrup is hung the loading stirrup by means of a ball-and-socket joint. When the stirrup is lowered gently, so that the ball rests upon the specimen, the loading stirrup becomes free and disconnected from the suspension stirrup. At this stage the whole of the weight is upon the specimen, there being no parts in friction or rubbing contact. The upper hand-wheel is then turned back to take the load off the specimen, which can now be removed for the purpose of measuring the diameter of the impression by means of a high-power microscope with graduations of $\mathrm{I} / 200 \mathrm{~mm}$. on the graticule. The hardness numbers are calculated as in the ordinary Brinell test, the load being divided by the area of the impression, and are directly comparable with the usual Brinell numbers when a load proportional to the square of the ball diameter is employed.

The impressions are so small as to be scarcely perceptible to the eye, and tests may be made on parts of delicate mechanisms without injury to the part tested. Loaded small-arm cartridge-cases may be tested without removal of bullet or charge. The hardness of wire at successive stages of drawing can be measured. Cutlery blades, however thin, may be tested, and the hardness of a cutting tool may be determined close to the cutting edge. Interesting applications of this microscopic Brinell test have been made in the exploration of strain-hardening, for when a metal object has been unequally strained the distribution of strain will usually be indicated by differences in hardness from point to point.

Attention may also be directed to the micro-Brinell apparatus developed by the Ordnance Department of the U.S. Army (Bureau of Standards, Bulletin I6, I 920 , p. 557). This has been used with a load of I5 kg. for 30 seconds upon a ball $\mathrm{I} / \mathrm{I} 6$ in. in diameter for measuring the hardness of individual crystals or small aggregates in annealed carbon steels.

H. S. A.

\section{The Coal-mining Industry.}

\section{By Prof. H. Louis.}

$\mathrm{T}$ E July issue of the Quarterly Review contains an article upon the recent coal dispute by Dr. Arthur Shadwell, to which he has given the somewhat unfortunate title "The War of the Mines." Dr. Shadwell points out at the beginning that this dispute was really not a war, and that there was in reality no need at all for a difference, which might have been arranged by mutual concessions, to have degenerated into industrial strife. He recognises that this was not a case of the men striking against any arbitrary action of the employers, but was rather an expression of their irritation at the inevitable development of the economic situation, and he states clearly and definitely the only remedy: "There is only one NO. 2702 , VOL. 107$]$ way out-the way of work. Other nations in a similar position have taken it; they are at work, and working hard. Here less work is being done than ever before."

It is pointed out quite correctly that the mining industry is distinguishing itself above all others in the readiness with which it resorts to industrial strife, and that the real cause of many of these difficulties, and the basal reason for the present grave position of the coal industry, are to be sought in the Minimum Wage Act of I9I1, which is accurately described as "the first instance of a minimum wage established by Parliament in an industry in which the workmen are well organised and able to protect themselves." 